ISSN 2078-3744. Вісник Львів. ун-ту. Серіл мех.-мат. 2018. Випуск 85. С. $107-119$

Visnyk of the Lviv Univ. Series Mech. Math. 2018. Issue 85. P. 107-119

http://publications.lnu.edu.ua/bulletins/index.php/mmf

doi: http://dx.doi.org/10.30970/vmm.2018.85.107-119

УДК 517.95

\title{
ON INITIAL-BOUNDARY VALUE PROBLEM FOR NONLINEAR INTEGRO-DIFFERENTIAL STOKES SYSTEM
}

\author{
Oleh BUHRII, Mariana KHOMA \\ Ivan Franko National University of Lviv, \\ Universytetska Str., 1, Lviv, 79000 \\ e-mail: oleh.buhrii@lnu.edu.ua, marianna.khoma88@gmail.com
}

Some nonlinear integro-differential Stokes system is considered. The initialboundary value problem for this system is investigated and the existence and uniqueness of the weak solution for the problem is proved.

Key words: evolution Stokes system, integro-differential equation, initialboundary value problem, weak solution.

\section{INTRODUCTION}

Let $n \in \mathbb{N}$ and $T>0$ be fixed numbers, $n \geq 2, \Omega \subset \mathbb{R}^{n}$ be a bounded domain with the smooth boundary $\partial \Omega, Q_{0, T}:=\Omega \times(0, T), \Sigma_{0, T}:=\partial \Omega \times(0, T), \Omega_{\tau}:=\{(x, t) \mid x \in \Omega$, $t=\tau\}, \tau \in[0, T]$. We seek a weak solution $\{u, \pi\}$ of the problem

$$
\begin{gathered}
u_{t}-\sum_{i, j=1}^{n}\left(A_{i j}(x, t) u_{x_{i}}\right)_{x_{j}}+G(x, t)|u|^{q-2} u+\int_{\Omega} \mathfrak{Z}(x, t, y) u(y, t) d y+ \\
+\nabla \pi(x, t)=F(x, t), \quad(x, t) \in Q_{0, T}, \\
\operatorname{div} u=0, \quad(x, t) \in Q_{0, T}, \\
\int_{\Omega} \pi(x, t) d x=0, \quad t \in(0, T), \\
\left.u\right|_{\Sigma_{0, T}}=0, \\
\left.u\right|_{t=0}=u_{0}(x), \quad x \in \Omega .
\end{gathered}
$$

2010 Mathematics Subject Classification: 35K55, 35D30, 76D07, 47G20

(c) Buhrii, O., Khoma, M., 2018 
Here $u=\left(u_{1}, \ldots, u_{n}\right): Q_{0, T} \rightarrow \mathbb{R}^{n}$ is the velocity field, $|u|=\left(\left|u_{1}\right|^{2}+\ldots+\left|u_{n}\right|^{2}\right)^{1 / 2}$, $\operatorname{div} u=\frac{\partial u_{1}}{\partial x_{1}}+\ldots+\frac{\partial u_{n}}{\partial x_{n}}, \pi: Q_{0, T} \rightarrow \mathbb{R}$ is the pressure, $\nabla \pi=\left(\frac{\partial \pi}{\partial x_{1}}, \ldots, \frac{\partial \pi}{\partial x_{n}}\right)$, and $q>1$ is some number which is called an exponent of the nonlinearity of system (1).

The linearized version of the Navier-Stokes system is called the Stokes system. It is well known that these equations describe the time evolution of the solutions to the mathematical models of the viscous incompressible fluids. For more details about the physical meaning of the Navier-Stokes and Stokes systems see [1], [2, etc. The initialboundary value problem for the Stokes system is considered in [3], [4], [5], [6, [7, [8], [9] (see also the references given there).

To take into account of some elasticity aspect of the non-Newtonian viscous fluids, the well-known classical Navier-Stokes equations are perturbed by an integral term which means the past history of the fluid (see [10]). The problems for the Navier-Stokes system with the integral memory term of the type

$$
u_{t}+\sum_{k=1}^{n} v_{k} v_{x_{k}}-\alpha \Delta u-\int_{0}^{t} K_{1}(t, \tau) \Delta u d \tau-\int_{\Omega} K_{2}(t, y) \Delta u d y+\nabla \pi=F,
$$

where $\Delta u$ is a Laplacian, is considered in [11] if either $K_{2} \equiv 0$, or $\alpha=0$ and $K_{1} \equiv 0$.

We perturb the classical Stokes equations by the monotonous nonlinear term and the linear integral term. We seek a weak solution to the initial-boundary value problem (1)-(5). As we know this problem is not studied yet. The paper is organized as follows. In Section 22 we formulate the considered problem and main results. The auxiliary statements are given in Section 3 . Finally, in Section 4 we prove the main results.

\section{StATEMENT OF PRoblem AND FORMulation of MAIN RESUlts}

Let $(\cdot, \cdot)_{\mathbb{R}^{n}}$ be a scalar product in the space $\mathbb{R}^{n}$,

$$
(u, v)_{\Omega}:=\int_{\Omega}(u(x), v(x))_{\mathbb{R}^{n}} d x, \quad u=\left(u_{1}, \ldots, u_{n}\right), v=\left(v_{1}, \ldots, v_{n}\right): \Omega \rightarrow \mathbb{R}^{n} .
$$

Take $s \in \mathbb{N}$. Let us consider the Sobolev space $\left[H^{s}(\Omega)\right]^{n}$ with the scalar product

$$
((u, v))_{s}:=\sum_{i=1}^{n}\left(u_{i}, v_{i}\right)_{H^{s}(\Omega)}, \quad u, v \in\left[H^{s}(\Omega)\right]^{n} .
$$

Let $C_{\mathrm{div}}:=\left\{u \in\left[C_{0}^{\infty}(\Omega)\right]^{n} \mid \operatorname{div} u=0\right\}$,

$$
\begin{gathered}
H \text { is the closure of } C_{\mathrm{div}} \text { in }\left[L^{2}(\Omega)\right]^{n}, \\
Z_{s} \text { is the closure of } C_{\mathrm{div}} \text { in }\left[H^{s}(\Omega)\right]^{n},
\end{gathered}
$$

where $\|h ; H\|:=\left\|h ;\left[L^{2}(\Omega)\right]^{n}\right\|=\sum_{l=1}^{n}\left\|h_{l} ; L^{2}(\Omega)\right\|, \quad h=\left(h_{1}, \ldots, h_{n}\right) \in H$, and $\left\|z ; Z_{s}\right\|:=\sqrt{((z, z))_{s}}, \quad z=\left(z_{1}, \ldots, z_{n}\right) \in Z_{s}$.

By definition, put

$$
V:=Z_{1} \cap\left[L^{q}(\Omega)\right]^{n}, \quad U\left(Q_{0, T}\right):=L^{2}\left(0, T ; Z_{1}\right) \cap\left[L^{q}\left(Q_{0, T}\right)\right]^{n} .
$$


Assume that the following conditions are fulfilled.

(A): $A_{i j}$ is an $n$-order square matrix with the elements from $L^{\infty}\left(Q_{0, T}\right) ; A_{i j}=A_{j i}$ $(i, j=\overline{1, n})$; for a.e. $(x, t) \in Q_{0, T}$ and for every $\xi^{1}, \ldots, \xi^{n} \in \mathbb{R}^{n}$, we get

$$
a_{0} \sum_{i=1}^{n}\left|\xi^{i}\right|^{2} \leq \sum_{i, j=1}^{n}\left(A_{i j}(x, t) \xi^{i}, \xi^{j}\right)_{\mathbb{R}^{n}} \leq a^{0} \sum_{i=1}^{n}\left|\xi^{i}\right|^{2} \quad\left(0<a_{0} \leq a^{0}<+\infty\right) ;
$$

$(\mathbf{G}): G$ is an $n$-order square matrix, $G=\operatorname{diag}\left(g_{1}, \ldots, g_{n}\right), g_{l} \in L^{\infty}\left(Q_{0, T}\right)$, and $0<g_{0} \leq g_{l}(x, t) \leq g^{0}<+\infty$ for a.e. $(x, t) \in Q_{0, T}$, where $l=\overline{1, n}$

$(\mathbf{E}): \mathfrak{Z}$ is an $n$-order square matrix with the elements from $L^{\infty}\left(Q_{0, T} \times \Omega\right)$;

(F): $F \in L^{2}(0, T ; H)$;

(U): $u_{0} \in H$.

We define the operators $A(t): V \rightarrow V^{*}, \mathcal{A}: U\left(Q_{0, T}\right) \rightarrow\left[U\left(Q_{0, T}\right)\right]^{*}$, $E(t):\left[L^{2}(\Omega)\right]^{n} \rightarrow\left[L^{2}(\Omega)\right]^{n}$, and $\mathrm{E}:\left[L^{2}\left(Q_{0, T}\right)\right]^{n} \rightarrow\left[L^{2}\left(Q_{0, T}\right)\right]^{n}$ by the rules:

$$
\begin{gathered}
\langle A(t) z, w\rangle_{V}:=\int_{\Omega}\left[\sum_{i, j=1}^{n}\left(A_{i j}(x, t) z_{x_{i}}(x), w_{x_{j}}(x)\right)_{\mathbb{R}^{n}}+\right. \\
\left.+\left(G(x, t)|z(x)|^{q-2} z(x), w(x)\right)_{\mathbb{R}^{n}}\right] d x, \quad z, w \in V, \quad t \in(0, T), \\
\langle\mathcal{A} u, v\rangle_{U\left(Q_{0, T}\right)}:=\int_{0}^{T}\langle A(t) u(t), v(t)\rangle_{V} d t, \quad u, v \in U\left(Q_{0, T}\right), \\
(E(t) z)(x):=\int_{\Omega} \mathfrak{Z}(x, t, y) z(y) d y, \quad x \in \Omega, \quad z \in\left[L^{2}(\Omega)\right]^{n}, \quad t \in(0, T), \\
(\mathrm{E} u)(x, t):=(E(t) u(t))(x)=\int_{\Omega} \mathfrak{Z}(x, t, y) u(y, t) d y, \quad(x, t) \in Q_{0, T}, u \in\left[L^{2}\left(Q_{0, T}\right)\right]^{n} .
\end{gathered}
$$

Let

$$
q>1, \quad s \in \mathbb{N}, \quad s \geq \max \left\{2, \frac{n}{2}, n\left(\frac{1}{2}-\frac{1}{q}\right)\right\}, \quad h=\min \left\{2, \frac{q}{q-1}\right\} .
$$

Note that 14 implies that $Z_{s} \bar{\circlearrowleft}\left(Z_{1} \cap\left[L^{q}(\Omega)\right]^{n}\right) \bar{J}$.

Definition 1. A pair of the functions $\{u, \pi\}$ is called a weak solution of problem (1)-(5), if $u \in U\left(Q_{0, T}\right) \cap C\left([0, T] ; Z_{s}^{*}\right), u_{t} \in\left[U\left(Q_{0, T}\right)\right]^{*}, \pi \in L^{h}\left(Q_{0, T}\right), u$ satisfies $\left[5\right.$ in $Z_{s}^{*}$, for $v \in V$ and $t \in(0, T)$ we have

$$
\left\langle u_{t}(t), v\right\rangle_{V}+\langle A(t) u(t), v\rangle_{V}+(E(t) u(t), v)_{\Omega}=(F(t), v)_{\Omega},
$$

$\pi$ satisfies (1) in $D^{*}\left(Q_{0, T}\right)$, and $\pi$ satisfies (3) in $D^{*}(0, T)$.

Theorem 1 (existence). Let conditions (A)-(U) hold. Then problem (1)-(5) has a weak solution $\{u, \pi\}$. Moreover, $u \in L^{\infty}(0, T ; H)$ and $\nabla \pi \in L^{h}\left(0, T ;\left[W^{-1, s}(\Omega)\right]^{n}\right)$.

Theorem 2 (uniqueness). Let conditions (A)-(E) hold. Then, problem (1)-(5) cannot have more than one weak solution. 


\section{Auxiliary statements}

For Banach spaces $X$ and $Y$ the notation $X \circlearrowleft Y$ means the continuous embedding; the notation $X \bar{\circlearrowleft} Y$ means a continuous and dense embedding; the notation $X \stackrel{K}{\subset} Y$ means a compact embedding.

3.1. Projection operator. Let $\mathcal{H}$ be a Hilbert space with a scalar product $(\cdot, \cdot)_{\mathcal{H}}, \mathcal{V}$ be a reflexive separable Banach space, $\mathcal{V} \circlearrowleft \mathcal{H} \cong \mathcal{H}^{*} \bar{\circlearrowleft} \mathcal{V}^{*},\left\{w^{j}\right\}_{j \in \mathbb{N}}$ be an orthonormal basis for the space $\mathcal{H}, m \in \mathbb{N}$ be a fixed number, and $\mathfrak{M}$ be the set of all linear combinations of the elements from $\left\{w^{1}, \ldots, w^{m}\right\}$. Define a unique orthogonal projection $P_{m}: \mathcal{H} \rightarrow \mathfrak{M}$ by the rule (see [12, p. 527])

$$
P_{m} h:=\sum_{j=1}^{m}\left(h, w^{j}\right)_{\mathcal{H}} w^{j}, \quad h \in \mathcal{H} .
$$

This is a linear self-adjoint continuous operator (see Theorem 7.3.6 [12, p. 515]). If $\left\{w^{j}\right\}_{j \in \mathbb{N}} \subset \mathcal{V}$, then let us define an operator $\widehat{P}_{m}: \mathcal{V} \rightarrow \mathcal{V}$ (not necessarily self-adjoint) by the rule

$$
\widehat{P}_{m} v:=P_{m} v \text { for every } v \in \mathcal{V} .
$$

For a conjugate operator $\widehat{P}_{m}^{*}: \mathcal{V}^{*} \rightarrow \mathcal{V}^{*}$ we have $\widehat{P}_{m}^{*}\left(\mathcal{V}^{*}\right) \subset \mathcal{V}($ see [13, p. 865]).

Proposition 1 (Lemma 3.9 [13, p. 865-866]). Assume that $\left\{w^{j}\right\}_{j \in \mathbb{N}}$ is an orthonormal basis for the space $\mathcal{H}$ such that $\left\{w^{j}\right\}_{j \in \mathbb{N}} \subset \mathcal{V}, \psi_{1}^{m}, \ldots, \psi_{m}^{m} \in \mathbb{R}$ are some numbers, and $F \in \mathcal{V}^{*}$. Then $z^{m}:=\sum_{s=1}^{m} \psi_{s}^{m} w^{s} \in \mathcal{V}$ satisfies

$$
\left\{\begin{array}{c}
\left\langle z^{m}, w^{1}\right\rangle_{\mathcal{V}}=\left\langle F, w^{1}\right\rangle_{\mathcal{V}}, \\
\vdots \\
\left\langle z^{m}, w^{m}\right\rangle_{\mathcal{V}}=\left\langle F, w^{m}\right\rangle_{\mathcal{V}},
\end{array}\right.
$$

if the following equality holds

$$
z^{m}=\widehat{P}_{m}^{*} F \quad \text { in } \quad \mathcal{V}^{*} .
$$

Suppose that $H$ and $Z_{s}$ are determined from (8) and (9) respectively, where $s \in \mathbb{N}$. From [14, Ch. 1, §6.1], we obtain the embeddings

$$
Z_{s} \bar{\circlearrowleft} Z_{1} \circlearrowleft H \cong H^{*} \circlearrowleft Z_{1}^{*} \circlearrowleft Z_{s}^{*} \text {. }
$$

Moreover, $Z_{s} \subset\left[H_{0}^{s}(\Omega)\right]^{n}$. Let $\left\{w^{\mu}\right\}_{\mu \in \mathbb{N}}$ be a set of all eigenfunctions of the problem

$$
((w, v))_{s}=\lambda(w, v)_{H} \quad \forall v \in Z_{s},
$$

$\left\{\lambda_{\mu}\right\}_{\mu \in \mathbb{N}} \subset \mathbb{R}_{>0}:=\{\lambda \in \mathbb{R} \mid \lambda>0\}$ be a set of the corresponding eigenvalues. For the sake of convenience we have assumed that $\left\{w^{\mu}\right\}_{\mu \in \mathbb{N}}$ is an orthonormal set in $H$.

Proposition 2 (see [14, Ch. 1, §6.3]). If $s \in \mathbb{N}$ and $s \geq \frac{n}{2}$, then the set $\left\{w^{\mu}\right\}_{\mu \in \mathbb{N}}$ of all eigenfunction of problem 20 is a basis for the space $Z_{s}$.

The following Lemma is needed for the sequel. 
Lemma 1. Suppose that $P_{m}$ and $\widehat{P}_{m}$ are determined from (16) and 17 respectively, where $\mathcal{H}=H, \mathcal{V}=Z_{s}, s \in \mathbb{N}$, and $\left\{w^{\mu}\right\}_{\mu \in \mathbb{N}}$ is an orthonormal basis for the space $H$ that consists of all eigenfunctions of problem 20 . Then, for every $w \in L^{r}\left(0, T ; Z_{s}^{*}\right)$ and $r>1$, we have the inequality

$$
\left\|\widehat{P}_{m}^{*} w ; L^{r}\left(0, T ; Z_{s}^{*}\right)\right\| \leq\left\|w ; L^{r}\left(0, T ; Z_{s}^{*}\right)\right\| .
$$

Proof. From [14, Ch. 1, §6.4.3], we get that

$$
\left\|\widehat{P}_{m} z\right\|_{Z_{s}} \leq\|z\|_{Z_{s}}, \quad z \in Z_{s} .
$$

Since $\left\|D^{*}\right\|_{\mathcal{L}\left(B^{*}, A^{*}\right)}=\|D\|_{\mathcal{L}(A, B)}$ for every $D \in \mathcal{L}(A, B)$ (see [15, p. 231]), using [22], we have

$$
\left\|\widehat{P}_{m}^{*} v\right\|_{Z_{s}^{*}} \leq\|v\|_{Z_{s}^{*}}, \quad v \in Z_{s}^{*}
$$

Hence, $\int_{0}^{T}\left\|\widehat{P}_{m}^{*} w(t)\right\|_{Z_{s}^{*}}^{r} d t \leq \int_{0}^{T}\|w(t)\|_{Z_{s}^{*}}^{r} d t$ and so inequality 21 holds.

0.1. Cauchy's problem for system of ordinary differential equations. Take $\ell \in \mathbb{N}$ and $Q=(0, T) \times \mathbb{R}^{\ell}$. In this section we seek a weak solution $\varphi:[0, T] \rightarrow \mathbb{R}^{\ell}$ of the problem

$$
\varphi^{\prime}(t)+L(t, \varphi(t))=M(t), \quad t \in[0, T], \quad \varphi(0)=\varphi^{0},
$$

where $M:[0, T] \rightarrow \mathbb{R}^{\ell}$ and $L: Q \rightarrow \mathbb{R}^{\ell}$ are some functions (for the sake of convenience we have assumed that $L(t, 0)=0$ for every $t \in[0, T])$, and $\varphi^{0}=\left(\varphi_{1}^{0}, \ldots, \varphi_{\ell}^{0}\right) \in \mathbb{R}^{\ell}$.

Proposition 3 (the Carathéodory-LaSalle Theorem, see Theorem 3.24 [13, p. 872]). Suppose that $p \geq 2$, the function $L: Q \rightarrow \mathbb{R}^{\ell}$ satisfies $L^{p}$-Carathéodory condition, $M \in$ $L^{p}\left(0, T ; \mathbb{R}^{\ell}\right)$, and $\varphi^{0} \in \mathbb{R}^{\ell}$. If there exist nonnegative functions $\alpha, \beta \in L^{1}(0, T)$ such that for every $\xi \in \mathbb{R}^{\ell}$ and for a.e. $t \in[0, T]$ the inequality

$$
(L(t, \xi), \xi)_{\mathbb{R}^{\ell}} \geq-\alpha(t)|\xi|^{2}-\beta(t)
$$

holds, then problem 24 has a global weak solution $\varphi \in W^{1, p}\left(0, T ; \mathbb{R}^{\ell}\right)$.

3.2. Additional statements. Let $\mathbb{Z}_{\geq-1}:=\{s \in \mathbb{Z} \mid s \geq-1\}$. The following Propositions are needed for the sequel.

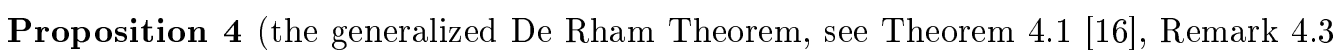
[16], and Lemma 2 [17]). Suppose that $\Omega$ be an open bounded connected and Lipschitz subset of $\mathbb{R}^{n}, T>0, s_{1}, s_{2} \in \mathbb{Z}_{\geq-1}, h_{1}, h_{2} \in[1, \infty]$, and $\mathcal{F} \in W^{s_{1}, h_{1}}\left(0, T ;\left[W^{s_{2}, h_{2}}(\Omega)\right]^{n}\right)$. Then, if

$$
\langle\mathcal{F}(\cdot), v\rangle_{[D(\Omega)]^{n}}=0 \text { in } D^{*}(0, T)
$$

for all $v \in \mathcal{V}=\left\{v \in\left[C_{0}^{\infty}(\Omega)\right]^{n} \mid \operatorname{div} v=0\right\}$, then there exists a unique

$$
\pi \in W^{s_{1}, h_{1}}\left(0, T ; W^{s_{2}+1, h_{2}}(\Omega)\right)
$$

such that

$$
\begin{gathered}
\nabla \pi=\mathcal{F} \quad \text { in } \quad\left[D^{*}\left(Q_{0, T}\right)\right]^{n}, \\
\int_{\Omega} \pi(\cdot) d x=0 \quad \text { in } \quad D^{*}(0, T) .
\end{gathered}
$$

Moreover, there exists a positive number $C_{\square}$ (independent of $\mathcal{F}, \pi$ ) such that

$$
\left\|\pi ; W^{s_{1}, h_{1}}\left(0, T ; W^{s_{2}+1, h_{2}}(\Omega)\right)\right\| \leq C_{1}\left\|\mathcal{F} ; W^{s_{1}, h_{1}}\left(0, T ;\left[W^{s_{2}, h_{2}}(\Omega)\right]^{n}\right)\right\| .
$$


Proposition 5 (the Aubin theorem, see [18] and [19] p. 393]). If $s, h \in(1, \infty)$ are fixed numbers, $\mathcal{W}, \mathcal{L}, \mathcal{B}$ are Banach spaces, and $\mathcal{W} \stackrel{K}{\subset} \mathcal{L} \circlearrowleft \mathcal{B}$, then

$$
\left\{u \in L^{s}(0, T ; \mathcal{W}) \mid u_{t} \in L^{h}(0, T ; \mathcal{B})\right\} \stackrel{K}{\complement}\left[L^{s}(0, T ; \mathcal{L}) \cap C([0, T] ; \mathcal{B})\right] .
$$

Proposition 6 (Lemma 1.18 [20, p. 39]). If $u^{m} \underset{m \rightarrow \infty}{\longrightarrow} u$ in $L^{p}\left(Q_{0, T}\right)(1 \leq p \leq \infty)$, then there exists a subsequence (we call it $\left\{u^{m}\right\}_{m \in \mathbb{N}}$ again) such that $u^{m} \underset{m \rightarrow \infty}{\longrightarrow}$ u a.e. in $Q_{0, T}$.

It is clear that if $u=\left(u_{1}, \ldots, u_{n}\right) \in\left[L^{2}(\mathcal{O})\right]^{n}$, where $\mathcal{O}=\Omega$ or $\mathcal{O}=Q_{0, T}$, then

$$
\left\||u| ; L^{2}(\mathcal{O})\right\|^{2}=\int_{\mathcal{O}}|u|^{2} d y=\sum_{l=1}^{n}\left\|u_{l} ; L^{2}(\mathcal{O})\right\|^{2} \leq n\left\|u ;\left[L^{2}(\mathcal{O})\right]^{n}\right\|^{2},
$$

and so

$$
\left\||u| ; L^{2}(\mathcal{O})\right\| \leq \sqrt{n}\left\|u ;\left[L^{2}(\mathcal{O})\right]^{n}\right\| .
$$

Lemma 2. If condition $(\mathbf{E})$ holds, then the operators $\mathrm{E}:\left[L^{2}\left(Q_{0, T}\right)\right]^{n} \rightarrow\left[L^{2}\left(Q_{0, T}\right)\right]^{n}$ and $E(t):\left[L^{2}(\Omega)\right]^{n} \rightarrow\left[L^{2}(\Omega)\right]^{n}$, where $t \in(0, T)$, are linear bounded and continuous. Moreover, there exists a constant $E^{0}>0$ such that for every $z \in\left[L^{2}(\Omega)\right]^{n}, t \in(0, T)$, $u \in\left[L^{2}\left(Q_{0, T}\right)\right]^{n}$, and $\tau \in(0, T]$, the following estimates are true:

$$
\begin{gathered}
\left\||E(t) z| ; L^{2}(\Omega)\right\| \leq E^{0}\left\||z| ; L^{2}(\Omega)\right\| \leq \sqrt{n} E^{0}\left\|z ;\left[L^{2}(\Omega)\right]^{n}\right\| ; \\
\left\||\mathrm{E} u| ; L^{2}\left(Q_{0, \tau}\right)\right\| \leq E^{0}\left\||u| ; L^{2}\left(Q_{0, \tau}\right)\right\| \leq \sqrt{n} E^{0}\left\|u ;\left[L^{2}\left(Q_{0, \tau}\right)\right]^{n}\right\| .
\end{gathered}
$$

Proof. It follows from the Cauchy-Bunyakowski-Schwarz inequality and (E) that

$$
\begin{gathered}
\left\||E(t) z| ; L^{2}(\Omega)\right\|^{2}=\int_{\Omega}|(E(t) z)(x)|^{2} d x=\int_{\Omega}\left|\int_{\Omega} \mathfrak{Z}(x, t, y) z(y) d y\right|^{2} d x \leq \\
\leq \int_{\Omega}\left|\int_{\Omega}\|\mathfrak{Z}(x, t, y)\|_{n} \cdot\right| z(y)|d y|^{2} d x \leq \int_{\Omega}\left(\left.\int_{\Omega}|| \mathfrak{Z}(x, t, y)\right|_{n} ^{2} d y\right)\left(\int_{\Omega}|z(y)|^{2} d y\right) d x \leq \\
\leq\left|E^{0}\right|^{2} \int_{\Omega}|z(y)|^{2} d y=\left|E^{0}\right|^{2}|||z| ; L^{2}(\Omega) \|^{2},
\end{gathered}
$$

where $E^{0}=\underset{t \in(0, T)}{\operatorname{ess} \sup _{\Omega}}\left(\int_{\Omega} d x \int_{\Omega}\|\mathfrak{Z}(x, t, y)\|_{n}^{2} d y\right)^{1 / 2}$ and $\|\cdot\|_{n}$ means a norm of the square matrix. Thus, using (31), we get 32 . Estimate 33 is proved in a similar way.

Lemma 3. Let conditions (A)-(E) hold, $\left\{w^{j}\right\}_{j \in \mathbb{N}} \subset V, m \in \mathbb{N}, L=\left(L_{1}, L_{2}, \ldots, L_{m}\right)$, $L_{\mu}(t, \xi)=\left\langle A(t) z^{m}, w^{\mu}\right\rangle_{V}+\left(E(t) z^{m}, w^{\mu}\right)_{\Omega}, \quad \mu=\overline{1, m}, \quad t \in(0, T), \quad \xi \in \mathbb{R}^{m}$, and $z^{m}(x)=\sum_{\mu=1}^{m} \xi_{\mu} w^{\mu}(x)$ for $x \in \Omega$. Then

$$
(L(t, \xi), \xi)_{\mathbb{R}^{m}} \geq \int_{\Omega}\left[a_{0} \sum_{i=1}^{n}\left|z_{x_{i}}^{m}\right|^{2}+g_{0}\left|z^{m}\right|^{q}-E^{0}\left|z^{m}\right|^{2}\right] d x, \quad t \in(0, T), \quad \xi \in \mathbb{R}^{m} .
$$


Proof. It is clear that

$$
(L(t, \xi), \xi)_{\mathbb{R}^{m}}=\left\langle A(t) z^{m}, z^{m}\right\rangle_{V}+\left(E(t) z^{m}, z^{m}\right)_{\Omega} .
$$

If we use conditions $(\mathbf{A})$ and $(\mathbf{G})$, then we get

$$
\begin{gathered}
\left\langle A(t) z^{m}, z^{m}\right\rangle_{V}=\int_{\Omega}\left[\sum_{i, j=1}^{n}\left(A_{i j}(x, t) z_{x_{i}}^{m}(x), z_{x_{j}}^{m}(x)\right)_{\mathbb{R}^{n}}+\right. \\
\left.+\left(G(x, t)\left|z^{m}(x)\right|^{q-2} z^{m}(x), z^{m}(x)\right)_{\mathbb{R}^{n}}\right] d x \geq \int_{\Omega}\left[a_{0} \sum_{i=1}^{n}\left|z_{x_{i}}^{m}\right|^{2}+g_{0}\left|z^{m}\right|^{q}\right] d x .
\end{gathered}
$$

Using (31) and (32), we obtain

$$
\begin{array}{r}
\quad\left|\left(E(t) z^{m}, z^{m}\right)_{\Omega}\right|=\left|\int_{\Omega}\left(E(t) z^{m}, z^{m}\right)_{\mathbb{R}^{n}} d x\right| \leq \int_{\Omega}\left|E(t) z^{m}\right| \cdot\left|z^{m}\right| d x \leq \\
\leq||\left|E z^{m}\right| ; L^{2}(\Omega)|| \cdot||\left|z^{m}\right| ; L^{2}(\Omega)|| \leq E^{0}||\left|z^{m}\right| ;\left.L^{2}(\Omega)\right|^{2}=E^{0} \int_{\Omega}\left|z^{m}\right|^{2} d x .
\end{array}
$$

Thus, (35)-(37) imply that (34) holds.

\section{Proofs of main Results}

Proof of Theorem 1 The solution will be constructed via Faedo-Galerkin's method.

Step 1 (construction of approximation). Let $\left\{w^{\mu}\right\}_{\mu \in \mathbb{N}}$ and $Z_{s}$ be taken from Proposition 2, $s \in \mathbb{N}$ satisfies 14. By definition, put

$$
u^{m}(x, t):=\sum_{\mu=1}^{m} \varphi_{\mu}^{m}(t) w^{\mu}(x), \quad(x, t) \in Q_{0, T}, \quad m \in \mathbb{N},
$$

where the unknown function $\varphi:=\left(\varphi_{1}^{m}, \ldots, \varphi_{m}^{m}\right)$ satisfies

$$
\begin{gathered}
\left(u_{t}^{m}(t), w^{\mu}\right)_{\Omega}+\left\langle A(t) u^{m}(t), w^{\mu}\right\rangle_{V}+\left(E(t) u(t), w^{\mu}\right)_{\Omega}=\left(F(t), w^{\mu}\right)_{\Omega}, t \in(0, T), \mu=\overline{1, m}, \\
\varphi_{1}^{m}(0)=\alpha_{1}^{m}, \quad \ldots, \quad \varphi_{m}^{m}(0)=\alpha_{m}^{m} .
\end{gathered}
$$

Here the numbers $\alpha_{1}^{m}, \ldots, \alpha_{m}^{m} \in \mathbb{R}$ are chosen so that, $u_{0}^{m} \underset{m \rightarrow \infty}{\longrightarrow} u_{0}$ strongly in $H$, where $u_{0}^{m}(x):=\sum_{j=1}^{m} \alpha_{j}^{m} w^{j}(x), \quad x \in \Omega$. It is clear that the condition

$$
u^{m}(0)=u_{0}^{m}
$$

holds. Let us show that the mentioned function $\varphi$ exists. Let $L$ be a vector-valued function from Lemma 3. Then Cauchy problem (38)- $\sqrt{39}$ takes form $(24)$ if $M(t)=\left(\left(F(t), w^{1}\right)_{\Omega}\right.$, $\left.\ldots,\left(F(t), w^{m}\right)_{\Omega}\right), \quad t \in(0, T)$. It follows from condition $(\mathbf{F})$ that $M \in L^{2}\left(0, T ; \mathbb{R}^{m}\right)$. Conditions (A)-(E) yield that the function $L$ satisfies $L^{\infty}$-Carathéodory condition.

Using estimate (34), conditions $a_{0}>0$ and $g_{0}>0$, and the orthogonality of the basis $\left\{w^{\mu}\right\}_{\mu \in \mathbb{N}}$ in $H$, we receive:

$$
\left(L\left(t, \varphi^{m}\right), \varphi^{m}\right)_{\mathbb{R}^{m}} \geq-E^{0} \int_{\Omega_{t}}\left|u^{m}\right|^{2} d x=-E^{0} \int_{\Omega_{t}} \sum_{\mu=1}^{m}\left|\varphi_{\mu}^{m}\right|^{2}\left|w^{\mu}\right|^{2} d x \geq-C_{2}\left|\varphi^{m}\right|^{2},
$$


where $C_{2}>0$ is independent of $t, \varphi^{m}$. Then estimate 25 with $\alpha(t) \equiv C_{2}$ and $\beta(t) \equiv 0$ is performed, and from the Carathéodory-LaSalle theorem (see Proposition 3) we have that $\varphi \in H^{1}\left(0, T ; \mathbb{R}^{m}\right)$ is a solution of problem $(24)$ and therefore problem $(38)-(39)$.

Step 2 (getting of estimates). Multipling the $\mu$-th equation of $(38)$ by $\varphi_{\mu}^{m}(t)$ and summing $\mu=\overline{1, m}$, we get:

$$
\begin{aligned}
\sum_{\mu=1}^{m}\left(u_{t}^{m}(t), w^{\mu} \varphi_{\mu}^{m}(t)\right)_{\Omega} & +\sum_{\mu=1}^{m}\left\langle A(t) u^{m}(t), w^{\mu} \varphi_{\mu}^{m}(t)\right\rangle_{V}+\sum_{\mu=1}^{m}\left(E(t) u^{m}(t), w^{\mu} \varphi_{\mu}^{m}(t)\right)_{\Omega}= \\
& =\sum_{\mu=1}^{m}\left(F(t), w^{\mu} \varphi_{\mu}^{m}(t)\right)_{\Omega}, \quad t \in(0, T) .
\end{aligned}
$$

After integrating for $t \in(0, \tau) \subset(0, T)$ and some transformation, we receive:

$$
\begin{gathered}
\int_{Q_{0, \tau}}\left[\left(u_{t}^{m}, u^{m}\right)_{\mathbb{R}^{n}}+\sum_{i, j=1}^{n}\left(A_{i j} u_{x_{i}}^{m}, u_{x_{j}}^{m}\right)_{\mathbb{R}^{n}}+\left(G\left|u^{m}\right|^{q-2} u^{m}, u^{m}\right)_{\mathbb{R}^{n}}+\left(\mathrm{E} u^{m}, u^{m}\right)_{\mathbb{R}^{n}}\right] d x d t= \\
=\int_{Q_{0, \tau}}\left(F, u^{m}\right)_{\mathbb{R}^{n}} d x d t, \quad \tau \in(0, T] .
\end{gathered}
$$

Clearly, using (40), we obtain:

$$
\int_{Q_{0, \tau}}\left(u_{t}^{m}, u^{m}\right)_{\mathbb{R}^{n}} d x d t=\int_{Q_{0, \tau}} \frac{1}{2} \frac{\partial}{\partial t}\left(\left|u^{m}\right|^{2}\right) d x d t=\frac{1}{2} \int_{\Omega_{\tau}}\left|u^{m}\right|^{2} d x-\frac{1}{2} \int_{\Omega}\left|u_{0}^{m}\right|^{2} d x .
$$

Using condition (A), we get the following estimate:

$$
\sum_{i, j=1}^{n}\left(A_{i j} u_{x_{i}}^{m}, u_{x_{j}}^{m}\right)_{\mathbb{R}^{n}} \geq a_{0} \sum_{i=1}^{n}\left|u_{x_{i}}^{m}\right|^{2}
$$

It follows from condition (G) that

$$
\left(G\left|u^{m}\right|^{q-2} u^{m}, u^{m}\right)_{\mathbb{R}^{n}}=\sum_{l=1}^{n} g_{l}(x, t)\left|u^{m}\right|^{q-2}\left|u_{l}^{m}\right|^{2} \geq g_{0} \sum_{l=1}^{n}\left|u^{m}\right|^{q-2}\left|u_{l}^{m}\right|^{2}=g_{0}\left|u^{m}\right|^{q} .
$$

Using the Cauchy-Bunyakowski-Schwarz inequality and (33), we obtain:

$$
\begin{aligned}
\left|\int_{Q_{0, \tau}}\left(\mathrm{E} u^{m}, u^{m}\right)_{\mathbb{R}^{n}} d x d t\right| & \leq \int_{Q_{0, \tau}}\left|\mathrm{E} u^{m}\right| \cdot\left|u^{m}\right| d x d t \leq||\left|\mathrm{E} u^{m}\right| ; L^{2}\left(Q_{0, \tau}\right)|| \cdot||\left|u^{m}\right| ; L^{2}\left(Q_{0, \tau}\right) \| \leq \\
\leq & E^{0}||\left|u^{m}\right| ;\left.L^{2}\left(Q_{0, \tau}\right)\right|^{2}=E^{0} \int_{Q_{0, \tau}}\left|u^{m}\right|^{2} d x d t .
\end{aligned}
$$

Clearly,

$$
\left|\left(F, u^{m}\right)_{\mathbb{R}^{n}}\right| \leq|F| \cdot\left|u^{m}\right| \leq \frac{|F|^{2}}{2}+\frac{\left|u^{m}\right|^{2}}{2} .
$$

Using (42)-(46), from equality (41), we obtain the following estimate:

$$
\frac{1}{2} \int_{\Omega}\left|u^{m}(x, \tau)\right|^{2} d x+\int_{Q_{0, \tau}}\left[a_{0} \sum_{l=1}^{n}\left|u_{x_{l}}^{m}\right|^{2}+g_{0}\left|u^{m}\right|^{q}\right] d x d t \leq
$$




$$
\leq \frac{1}{2} \int_{\Omega}\left|u_{0}^{m}\right|^{2} d x+\frac{1}{2} \int_{Q_{0, \tau}}|F|^{2} d x d t+\int_{Q_{0, \tau}}\left(\frac{1}{2}+E^{0}\right)\left|u^{m}\right|^{2} d x d t .
$$

Take $y(t):=\int_{\Omega}\left|u^{m}(x, t)\right|^{2} d x, \quad t \in[0, T]$. Then, from (47), we get an estimate:

$$
\frac{1}{2} y(\tau) \leq C_{3}+\left(\frac{1}{2}+E^{0}\right) \int_{0}^{\tau} y(t) d t, \quad \tau \in[0, T] .
$$

Therefore, the Gronwall lemma implies that $y(\tau) \leq C_{4}$, and so

$$
\int_{\Omega}\left|u^{m}(x, \tau)\right|^{2} d x \leq G, \quad \tau \in(0, T] .
$$

It follows from (47) and (48) that

$$
\int_{Q_{0, \tau}}\left[\sum_{i=1}^{n}\left|u_{x_{i}}^{m}\right|^{2}+|u|^{2}+|u|^{q}\right] d x d t \leq C_{5}, \quad \tau \in(0, T],
$$

This estimate yields that

$$
\left.\left.\int_{Q_{0, \tau}}|G| u^{m}\right|^{q-2} u^{m}\right|^{q^{\prime}} d x d t \leq C_{6} \int_{Q_{0, \tau}}\left|u^{m}\right|^{q} d x d t \leq C_{7} .
$$

From (33), 448), and (49) it follows the estimates

$$
\begin{gathered}
\left\|u^{m} ; L^{\infty}(0, T, H)\right\|+\left\|u^{m} ; U\left(Q_{0, T}\right)\right\| \leq C_{8}, \\
\left\|\mathrm{E} u^{m} ; L^{2}(0, T ; H)\right\| \leq C_{9}, \quad\left\|\mathrm{E} u^{m} ;\left[L^{2}\left(Q_{0, T}\right)\right]^{n}\right\| \leq C_{\mathbf{8}} .
\end{gathered}
$$

Here the constants $C_{3}, \ldots, C \frac{8}{8}$ are independent of $m$.

By (50)-(52) we have existence of the subsequence $\left\{u^{m_{k}}\right\}_{k \in \mathbb{N}} \subset\left\{u^{m}\right\}_{m \in \mathbb{N}}$ such that $u^{m_{k}} \underset{k \rightarrow \infty}{\longrightarrow} u *$-weakly in $L^{\infty}(0, T ; H)$ and weakly in $U\left(Q_{0, T}\right)$,

$$
\begin{gathered}
G\left|u^{m}\right|^{q-2} u^{m} \underset{k \rightarrow \infty}{\longrightarrow} \chi_{1} \quad \text { weakly in }\left[L^{q^{\prime}}\left(Q_{0, T}\right)\right]^{n}, \\
\mathrm{E} u^{m} \underset{k \rightarrow \infty}{\longrightarrow} \chi_{2} \text { weakly in }\left[L^{2}\left(Q_{0, T}\right)\right]^{n} .
\end{gathered}
$$

Step 3 (additional estimates). Estimate (49) implies the inequality

$$
\left\|\mathcal{A} u^{m} ;\left[U\left(Q_{0, T}\right)\right]^{*}\right\| \leq C_{10} .
$$

Since $s$ satisfies (14), from the construction of the space $U\left(Q_{0, T}\right)$, we obtain:

$$
\begin{gathered}
U\left(Q_{0, T}\right) \circlearrowleft L^{2}(0, T ; H) \circlearrowleft\left[U\left(Q_{0, T}\right)\right]^{*}, \\
L^{\max \{2, q\}}\left(0, T ; Z_{s}\right) \circlearrowleft L^{\max \{2, q\}}(0, T ; V) \circlearrowleft U\left(Q_{0, T}\right) \circlearrowleft L^{\min \{2, q\}}(0, T ; V) .
\end{gathered}
$$

Therefore,

$$
\left[U\left(Q_{0, T}\right)\right]^{*} \circlearrowleft L^{r}\left(0, T ; V^{*}\right) \circlearrowleft L^{r}\left(0, T ; Z_{s}^{*}\right), \quad r=\frac{\max \{2, q\}}{\max \{2, q\}-1} .
$$

Using (55) and (51), we obtain:

$$
\left\|u^{m} ; L^{\min \{2, q\}}(0, T ; V)\right\| \leq C_{11}\left\|u ; U\left(Q_{0, T}\right)\right\| \leq C_{12} .
$$


Using Proposition 1 and notation (10)-(13), (16), and (17), in same way as in [14, Ch. 1, $\S 5.3]$, we rewrite 38 as

$$
u_{t}^{m}=\widehat{P}_{m}^{*}\left(F-\mathcal{A} u^{m}-\mathrm{E} u^{m}\right) .
$$

Thus, from (58), estimate (21), embeddings (56) and (54), and estimates (52)-(53), we get:

$$
\begin{gathered}
\left\|u_{t}^{m} ; L^{r}\left(0, T ; Z_{s}^{*}\right)\right\|=\left\|\widehat{P}_{m}^{*}\left(F-\mathcal{A} u^{m}-\mathrm{E} u^{m}\right) ; L^{r}\left(0, T ; Z_{s}^{*}\right)\right\| \leq \\
\leq\left\|F-\mathcal{A} u^{m}-\mathrm{E} u^{m} ; L^{r}\left(0, T ; Z_{s}^{*}\right)\right\| \leq C_{13}\left\|F-\mathcal{A} u^{m}-\mathrm{E} u^{m} ;\left[U\left(Q_{0, T}\right)\right]^{*}\right\| \leq \\
\leq C_{14}\left(\left\|F ; L^{2}(0, T ; H)\right\|+\left\|\mathcal{A} u^{m} ;\left[U\left(Q_{0, T}\right)\right]^{*}\right\|+\left\|\mathrm{E} u^{m} ; L^{2}(0, T ; H)\right\|\right) \leq C_{15} .
\end{gathered}
$$

Here the constants $C_{10}, \ldots, C_{15}>0$ are independent of $m$.

Since $V \stackrel{K}{\complement} H \circlearrowleft Z_{s}^{*}$, from (57), (59), the Aubin theorem (see Proposition 5), and Proposition 6, we obtain:

$$
\begin{gathered}
u^{m_{k}} \underset{k \rightarrow \infty}{\longrightarrow} u \text { in } L^{\min \{2, q\}}(0, T ; H) \cap C\left([0, T] ; Z_{s}^{*}\right), \\
u^{m_{k}} \underset{k \rightarrow \infty}{\longrightarrow} u \text { almost everywhere in } Q_{0, T} .
\end{gathered}
$$

Therefore, (5) holds and $\chi_{1}=G|u|^{q-2} u$. Since $\mathrm{E}$ is a linear operator, we get $\chi_{2}=\mathrm{E} u$.

Step 4 (passing to the limit). Take $\psi \in C^{1}([0, T])$ such that $\psi(T)=0$. When we multiply equality $(38)$ by $\psi(t)$, integrate for $t \in(0, T)$, and integrate the first term by parts, we obtain the following:

$$
\begin{aligned}
& \int_{Q_{0, T}}\left[-\left(u^{m}, w^{\mu}\right)_{\mathbb{R}^{n}} \psi_{t}+\sum_{i, j=1}^{n}\left(A_{i j} u_{x_{i}}^{m}, w_{x_{j}}^{\mu}\right)_{\mathbb{R}^{n}} \psi+\left(G\left|u^{m}\right|^{q-2} u^{m}, w^{\mu}\right)_{\mathbb{R}^{n}} \psi+\right. \\
& \left.+\left(\mathrm{E} u^{m}, w^{\mu}\right)_{\mathbb{R}^{n}} \psi\right] d x d t=\int_{\Omega}\left(u_{0}^{m}, w^{\mu}\right)_{\mathbb{R}^{n}} \psi(0) d x+\int_{Q_{0, T}}\left(F, w^{\mu}\right)_{\mathbb{R}^{n}} \psi d x d t .
\end{aligned}
$$

Taking $m=m_{k}$ and letting $k \rightarrow \infty$, due to arbitrariness of $\psi$, we get 15 and

$$
\langle\mathcal{F}, z\rangle_{U\left(Q_{0, T}\right)}=0 \quad \forall z \in U\left(Q_{0, T}\right),
$$

where $\mathcal{F}:=F-u_{t}-\mathcal{A} u-E u$. Hence, $u_{t} \in\left[U\left(Q_{0, T}\right)\right]^{*}$. Taking $z(x, t)=w(x) \varphi(t), x \in \Omega$, $t \in(0, T)$, from $(60)$, we obtain:

$$
\int_{0}^{T}\langle\mathcal{F}(t), w\rangle_{[D(\Omega)]^{n}} \varphi(t) d t=0, \quad w \in[D(\Omega)]^{n}, \quad \varphi \in D(0, T),
$$

and so 26 holds. Clearly,

$$
\mathcal{F} \in L^{2}\left(0, T ;\left[H^{-1}(\Omega)\right]^{n}\right)+\left[L^{\frac{q}{q-1}}\left(Q_{0, T}\right)\right]^{n} \subset W^{0, h}\left(0, T ;\left[W^{-1, h}(\Omega)\right]^{n}\right),
$$

where $h$ is taken from (14). Then, the generalized De Rham theorem (see Proposition 4 ) yields that there exists $\pi \in W^{0, h}\left(0, T ; W^{0, h}(\Omega)\right)=L^{h}\left(Q_{0, T}\right)$ such that 28$)-29$ hold. Thus, $\pi$ satisfies (1) in $\left[D^{*}\left(Q_{0, T}\right)\right]^{n}$ and $(3)$ in $D^{*}(0, T)$. Theorem 1 is proved. 
Proof of Theorem [ Let $\left\{u_{1}, \pi_{1}\right\}$ and $\left\{u_{2}, \pi_{2}\right\}$ be weak solutions of problem (1)-(5). Set $u:=u_{1}-u_{2}$. Take (15) for $u_{1}$ :

$$
\left\langle u_{1 t}(t), v\right\rangle_{V}+\left\langle A(t) u_{1}(t), v\right\rangle_{V}+\left(E(t) u_{1}(t), v\right)_{\Omega}=(F(t), v)_{\Omega} .
$$

Take 15 for $u_{2}$ :

$$
\left\langle u_{2 t}(t), v\right\rangle_{V}+\left\langle A(t) u_{2}(t), v\right\rangle_{V}+\left(E(t) u_{2}(t), v\right)_{\Omega}=(F(t), v)_{\Omega} .
$$

Subtracting 62 from $(61)$, setting $v=u(t)$, and integrating for $t \in(0, \tau) \subset(0, T)$, we obtain:

$$
\begin{gathered}
\int_{0}^{\tau}\left[\left\langle u_{t}(t), u(t)\right\rangle_{V}+\left\langle A(t) u_{1}(t)-A(t) u_{2}(t), u_{1}(t)-u_{2}(t)\right\rangle_{V}+(E(t) u(t), u(t))_{\Omega}\right] d t= \\
=\int_{0}^{\tau}(F(t), v)_{\Omega} d t, \quad \tau \in(0, T] .
\end{gathered}
$$

After the simple transformations, in the same way as (47), from this equality, we get:

$$
\begin{gathered}
\frac{1}{2} \int_{\Omega_{\tau}}|u|^{2} d x+\int_{Q_{0, \tau}}\left[a_{0} \sum_{i=1}^{n}\left|u_{x_{i}}\right|^{2}+\left(G\left|u_{1}\right|^{q-2} u_{1}-G\left|u_{2}\right|^{q-2} u_{2}, u_{1}-u_{2}\right)_{\mathbb{R}^{n}}\right] d x d t \leq \\
\leq C_{16} \int_{Q_{0, \tau}}|u|^{2} d x d t, \quad \tau \in(0, T] .
\end{gathered}
$$

Let $y(\tau):=\int_{\Omega_{\tau}}|u|^{2} d x, \tau \in(0, T]$. Then, from $[63)$ it follows that $\frac{1}{2} y(\tau) \leq q_{16]} \int_{0}^{\tau} y(t) d t$, $\tau \in(0, T]$. Using the Gronwall lemma, we see that $y(\tau) \leq 0$ for $\tau \in[0, T]$, and so $u_{1}=u_{2}$.

Since $\left\{u_{1}, \pi_{1}\right\}$ and $\left\{u_{2}, \pi_{2}\right\}$ satisfy (1) in $D^{*}\left(Q_{0, T}\right)$, we obtain:

$$
\left(u_{1}-u_{2}\right)_{t}+\mathcal{A} u_{1}-\mathcal{A} u_{2}+\mathrm{E} u_{1}-\mathrm{E} u_{2}+\nabla\left(\pi_{1}-\pi_{2}\right)=0 .
$$

Then the equality $u_{1}=u_{2}$ yields that $\nabla\left(\pi_{1}-\pi_{2}\right)=0$. Therefore, for $t \in(0, T)$ we have that $\pi_{1}(t)-\pi_{2}(t)=C(t)$. It follows from condition (3) with $\pi_{1}$ and $\pi_{2}$ that $C(t)=0$. Thus, $\pi_{1}=\pi_{2}$ and Theorem 2 is proved.

\section{REFERENCES}

1. R. Temam, Navier-Stokes equations: theory and numerical analysis, Mir, Moscow, 1981 (Russian) (translated from: North-Holland Publ., Amsterdam, New York, Oxford, 1979).

2. M. Rǔžčka, Electrorheological fluids: Modeling and mathematical theory, Lect. Notes Math. 1748, Springer-Verlag, Berlin, 2000.

3. В. А. Солонников, Оценки решений нестационарной линеаризованной системъ уравнений Навъе-Стокса, Краевые задачи математической физики. 1, Сб. работ, Тр. МИАН CCCP 70 (1964), 213-317.

4. В. А. Солонников, Об оценках решений нестационарной задачи Стокса в анизотропнъх пространствах С. Л. Соболева и об оценках резолъвенты оператора Стокса, YMH 58 (2003), no. 2(350), 123-156 DOI: 10.4213/rm613; English version: V. A. Solonnikov, On estimates of solutions of the non-stationary Stokes problem in anisotropic Sobolev spaces and on estimates for the resolvent of the Stokes operator, Russian Math. Surveys. 58 (2003), no. 2, 331-365. DOI: 10.1070/RM2003v058n02ABEH000613 
5. V. A. Solonnikov. Weighted Schauder estimates for evolution Stokes problem, Ann. Univ. Ferrara 52 (2006), no. 1, 137-172. DOI: 10.1007/s11565-006-0012-7

6. И. Ш. Могилевский, О краевой задаче для нестационарной системъ Стокса с общими граничными условиями, Изв. АН СССР. Сер. матем. 50 (1986), no. 1, 37-66; English version: I. Sh. Mogilevskii. On a boundary value problem for the time-dependent Stokes system with general boundary conditions, Mathematics of the USSR-Izvestiya. 28 (1987), no. 1, 37-66. DOI: 10.1070/IM1987v028n01ABEH000866

7. G. P. Galdi, C. G. Simader, and H. Sohr, On Stokes problem in Lipschitz domain, Ann. Mat. Pura Appl. (4) 167 (1994), no. 1, 147-163. DOI: 10.1007/BF01760332

8. G. P. Galdi, C. G. Simader, and H. Sohr, A class of solution to stationary Stokes and NavierStokes equations with boundary data in $W^{-\frac{1}{q}, q}$, Math. Ann. 331 (2005). no. 1, 41-74. DOI: 10.1007/s00208-004-0573-7

9. O. M. Buhrii, Visco-plastic, Newtonian, and dilatant fluids: Stokes equations with variable exponent of nonlinearity, Mat. Stud. 49 (2018), no. 2, 165-180. DOI: $10.15330 / \mathrm{ms} .49 .2 .165-180$

10. I. Munteanu, Boundary stabilisation of the Navier-Stokes equation with fading memory, Intern. J. of Control. 88, №3 (2015) 531-542. DOI: 10.1080/00207179.2014.964780

11. N. A. Karazeeva, Solvability of initial boundary value problems for equations describing motions of linear viscoelastic fluids, J. Applied Math. 2005 (2005), no. 1, 59-80. DOI: $10.1155 / J A M .2005 .59$

12. E. Suhubi, Functional analysis, Kluwer Acad. Publ., Dordrecht, Boston, London, 2003.

13. O. Buhrii and N. Buhrii, Integro-differential systems with variable exponents of nonlinearity, Open Math. 15 (2017) 859-883. DOI: 10.1515/math-2017-0069

14. J.-L. Lions, Quelques méthodes de résolution des problémes aux limites non linéaires, Mir, Moscow, 1972 (translated from: Dunod Gauthier-Villars, Paris, 1969).

15. A. N. Kolmogorov and S. V. Fomin, Elements of theory of functions and functional analysis, Nauka, Moscow, 1972 (Russian).

16. J. A. Langa, J. Real, and J. Simon, Existence and regularity of the pressure for the stochastic Navier-Stokes equations, Appl. Math. Optim. 48 (2003), no. 3, 195-210. DOI: $10.1007 / \mathrm{s} 00245-003-0773-7$

17. J. Simon, Nonhomogeneous viscous incompressible fluids: existence of velocity, density and preassure, SIAM J. Math. Anal. 21 (1990), no. 5, 1093-1117. DOI: 10.1137/0521061

18. J.-P. Aubin, Un theoreme de compacite, Comptes rendus hebdomadaires des seances de l'academie des sciences. 256 (1963), no. 24, 5042-5044.

19. F. Bernis, Existence results for doubly nonlinear higher order parabolic equations on unbounded domains, Math. Ann. 279 (1988), no. 3, 373-394. DOI: 10.1007/BF01456275

20. H. Gajewski, K. Groger, and K. Zacharias. Nonlinear operator equations and operator differential equations, Mir, Moscow, 1978 (translated from: Akademie-Verlag, Berlin, 1974).

Стаття: надійшла до редколегї 28.08.2018

доопрацвована 12.09.2018

прийнята до друку 18.02.2018 
ON INITIAL-BOUNDARY VALUE PROBLEM FOR NONLINEAR ...

МІШАНА ЗАДАЧА ДЛЯ НЕЛІНІЙНӦ̈ ІНТЕГРО-ДИФЕРЕНЦАЛЬНОЇ СИСТЕМИ СТОКСА

\section{Олег БУГРІЙ, Мар'яна ХОМА}

Лъвівсъкий націоналъний університет імені Івана Франка, вул. Університетсъка, 1, Львів, 79000

e-mail: oleh.buhrii@lnu.edu.ua, marianna.khoma88@gmail.com

Розглянуто нелінійну інтегро-диференціальну систему рівнянь Стокса. Доведено існування та єдиність узагальненого розв'язку мішаної задачі для цієї системи.

Ключові слова: еволюційна система Стокса, інтегро-диференщіальне рівняння, мішана задача, узагальнений розв'язок. 